\title{
RESEARCH
}

\section{Inequalities in access to medical care by income in developed countries}

\section{Eddy van Doorslaer, Cristina Masseria, Xander Koolman for the OECD Health Equity Research Group}

$\infty \quad$ See related article page 187

\section{ABSTRACT}

Background: Most of the member countries of the Organization for Economic Cooperation and Development (OECD) aim to ensure equitable access to health care. This is often interpreted as requiring that care be available on the basis of need and not willingness or ability to pay. We sought to examine equity in physician utilization in 21 OECD countries for the year 2000.

Methods: Using data from national surveys or from the European Community Household Panel, we extracted the number of visits to a general practitioner or medical specialist over the previous 12 months. Visits were standardized for need differences using age, sex and reported health levels as proxies. We measured inequity in doctor utilization by income using concentration indices of the need-standardized use.

Results: We found inequity in physician utilization favouring patients who are better off in about half of the OECD countries studied. The degree of pro-rich inequity in doctor use is highest in the United States and Mexico, followed by Finland, Portugal and Sweden. In most countries, we found no evidence of inequity in the distribution of general practitioner visits across income groups, and where it does occur, it often indicates a pro-poor distribution. However, in all countries for which data are available, after controlling for need differences, people with higher incomes are significantly more likely to see a specialist than people with lower incomes and, in most countries, also more frequently. Pro-rich inequity is especially large in Portugal, Finland and Ireland.

Interpretation: Although in most OECD countries general practitioner care is distributed fairly equally and is often even pro-poor, the very pro-rich distribution of specialist care tends to make total doctor utilization somewhat pro-rich. This phenomenon appears to be universal, but it is reinforced when private insurance or private care options are offered.

CMAJ 2006;174(2):177-83

he member states of the Organization for Economic Cooperation and Development (OECD) represent the wealthiest and healthiest countries in the world. Most of them achieved nearly universal coverage of their populations for a fairly comprehensive package of medical services decades ago. Their governments are committed not only to pursuing the efficient delivery of high-quality medical care but also to ensuring equitable access to that care. In most OECD countries, access to good-quality physician services is ensured at relatively low and sometimes zero financial cost at the point of delivery. This is mainly the result of a variety of public insurance arrangements aimed at ensuring equitable access. The increasing tension between affordability and equity has spurred a number of countries to reconsider their public-private mix and to study reforms that may enhance efficiency while maintaining equity.

Like the World Health Organization, the OECD is committed to a watchful monitoring and comparison of the performance of its members' health care systems, and equity in access is regarded as a key objective. ${ }^{1}$ In 2002, the OECD Health Project commissioned a cross-country comparative study to assess how the very diverse health care delivery systems of its members fare in terms of equitable access. This article summarizes some of the main results of this study, and full details of the data and methods used can be found in the study published by the OECD. ${ }^{2}$

\section{Methods}

Most OECD countries finance the great majority of their essential health services from public sources ${ }^{3}$ and endorse the equity principle that these services ought to be allocated on the basis of need and not willingness or ability to pay. ${ }^{4}$ Therefore, a logical yardstick for international comparisons based on this principle of horizontal equity is the degree of inequality in use by income that remains after standardization for (measurable) need differences.

The data for Io European Union countries (Austria, Belgium, Denmark, Finland, Greece, Ireland, Italy, the Netherlands, Portugal and Spain) are taken from the 2000 wave of the European Community Household Panel (ECHP) survey conducted by Eurostat, the European Statistical Office. The survey is based on a standardized questionnaire and involves annual interviewing of a representative panel of households and people 16 years and older in each European Union member state. ${ }^{5}$ It covers a wide range of topics, including demographic characteristics, income, social transfers, health, housing, education and employment. The national surveys used for the other II countries are listed in Table I. Except for the United States 
Table 1: Surveys used for OECD countries to obtain study data

\begin{tabular}{|c|c|c|c|c|}
\hline Country & Survey & Year & $\begin{array}{l}\text { Sample } \\
\text { size }\end{array}$ & $\begin{array}{l}\text { Age } \\
\text { limit, yr }\end{array}$ \\
\hline Australia & National Health Survey & 2001 & 15516 & $\geq 16$ \\
\hline Austria & ECHP & 2000 & 5610 & $\geq 16$ \\
\hline Belgium & ECHP & 2000 & 4483 & $\geq 16$ \\
\hline Canada & Community Health Survey & 2001 & 107613 & $\geq 16$ \\
\hline Denmark & ECHP & 2000 & 3738 & $\geq 16$ \\
\hline Finland & ECHP & 2000 & 5587 & $\geq 16$ \\
\hline France & $\begin{array}{l}\text { Health and Insurance Survey linked } \\
\text { to social insurance records }\end{array}$ & 2000 & 4381 & $\geq 16$ \\
\hline Germany & Socio-Economic Panel & 2001 & 12961 & $\geq 16$ \\
\hline Greece & ECHP & 2000 & 8983 & $\geq 16$ \\
\hline Hungary & National Health Monitoring Survey & 2000 & 4404 & $\geq 18$ \\
\hline Ireland & ECHP & 2000 & 4601 & $\geq 16$ \\
\hline Italy & ECHP & 2000 & 14155 & $\geq 16$ \\
\hline Mexico & National Health Survey & 2001 & 153865 & $\geq 16$ \\
\hline Netherlands & ECHP & 2000 & 8706 & $\geq 16$ \\
\hline Norway & Level of living survey - panel & 2000 & 3709 & $16-80$ \\
\hline Portugal & ECHP & 2000 & 10276 & $\geq 16$ \\
\hline Sweden & Survey of living conditions & 2001 & 5054 & $16-80$ \\
\hline Spain & ECHP & 2000 & 12182 & $\geq 16$ \\
\hline Switzerland & National Health Survey & 2002 & 9827 & $\geq 18$ \\
\hline United Kingdom & British Household Panel Survey & 2001 & 13712 & $\geq 16$ \\
\hline United States & Medical Expenditure Panel Survey & 1999 & 16557 & $\geq 16$ \\
\hline
\end{tabular}

Note: $\mathrm{OECD}=$ Organization for Economic Cooperation and Development, ECHP = European Community Household Panel.

(1999), the surveys refer to 2000 or a more recent year, and all are nationally representative of the free-living adult population. They were selected on the basis of their suitability for this analysis and their comparability to the ECHP data.

Measurement of annual health care utilization was based on the ECHP question "During the past 12 months, about how many times have you consulted a general practitioner or a medical specialist?" Similar I2-month reference-period questions were used for the other countries, although not all surveys had all information. Some countries' surveys (Australia, Germany, Mexico, Sweden and the United States) did not distinguish between general practitioner (GP) and specialist visits.

Variation in the number of physician visits is explained using health, income and other factors. As predictors of need for care, we used age, sex, self-reported general health and the presence and degree of limitation of any chronic physical or mental health problem, illness or disability. Income was measured by disposable (i.e., after-tax) household income per equivalent adult. Some surveys (e.g., for Australia, Canada) provided only categorical income data. Other explanatory variables used in the analysis were education and activity status. Where available, 2 more policy-relevant variables were used: (private) health insurance coverage for medical care expenditures, and region of residence (as a proxy for availability of care) or urban-rural division. For most ECHP-based coun- tries, no health insurance information and only very limited regional identifier information were available.

For all types of care, we computed need-expected use - or use adjusted according to expected need - by running a linear regression for all people in the sample on the full set of explanatory variables. For need predictors, we used indicator variables for 9 age-sex groups, 4 self-assessed health groups, and 2 groups indicating the extent to which a person is hampered in his or her usual activities by a chronic condition or handicap. Need for care is then defined as a person's expected use of medical care on the basis of actual need characteristics, with the effects of all other variables "neutralized" by their being set at their sample means in the prediction stage. Need then indicates the amount of medical care a person would have received had that person been treated the same as others with the same need characteristics, on average. We have used sample weighted least squares estimation, since the inequity indices and quintile distributions obtained are very similar to those obtained using more sophisticated nonlinear models. ${ }^{2,6}$

To measure the degree of horizontal inequity in health care use we compared the actual observed distribution of medical care by income with the need-expected distribution of use. As such, the method assumes that the average treatment rates for each country, and the average treatment differences between people in unequal need, reflect the accepted overall "norm" for that country. In other words, this method looks only at relative inequalities in mean use levels by income after any need differences have been standardized for.

The degree of inequality in health care utilization can be measured using the concept of a concentration curve $e^{7,8}$ (Fig. I). This plots the cumulative distribution of use as a function of the cumulative distribution of the population ranked by its income. A distribution is equal if its concentration curve coincides with the diagonal. A curve that lies above the diagonal indicates that use is more concentrated among the poor. A concentration index measures the degree of inequality in actual use as the area between the curve and the diagonal. Our index of horizontal inequity (HI) is simply a concentration index of inequality in need-standardized use. Robust estimates of the concentration index and $\mathrm{HI}$ index and its standard error can easily be obtained by running a convenient (weighted least squares) regression of a transformation of the variable on relative rank in the income distribution. ${ }^{9}$ When the $\mathrm{HI}$ index equals zero, it indicates horizontal equity: people in equal need (but at different incomes) are treated equally. When the index is positive, it indicates pro-rich inequity, and when it is negative, it indicates pro-poor inequity. The latter means that lower-income people 
seem to be using more care than one would expect simply on the basis of reported need (i.e., morbidity). Decomposition analyses (not reported here) help to provide further detail on the explanatory factors driving the measured inequities. ${ }^{2}$

\section{Results}

We present graphical cross-country comparisons of the mean levels of use and concentration indices of need-standardized use for 2 measures of utilization: the annual probability of any visit and the mean annual visit frequency.

\section{Between-country differences in mean physician consultation fractions and frequencies}

We found important differences between countries in the proportion of the population reporting a visit to doctor. On average, more than $70 \%$ of the adult population of most countries visited a doctor within the previous I2 months (Fig. 2). The proportion was lower only in Greece (63\%), the United States (68\%) and, especially, Mexico (2r\%). The fraction visiting a GP was fairly stable at around $70 \%-80 \%$, except in Greece and Switzerland, but the fraction consulting a specialist shows much more variation, from as low as 20\% (Ireland) and 30\% (Denmark and Norway) to as high as $60 \%$ (Austria and France). Similarly large cross-country differences in the mean annual consultation rates are shown in Fig. 3. In high-use countries like Germany, Hungary, France, Belgium and Austria, the visit frequency is around 7-8 doctor visits per year, which is twice the number in low-use countries like Finland, Switzerland, Denmark and the United States. Also noteworthy is the variation in the composition of total visits. For example, although the total number of doctor visits was the same in Greece and Ireland, the number of GP visits was only slightly higher than the number of specialist visits in Greece but was 7 times higher in Ireland. One might expect these cross-country differences in utilization frequencies to be largely determined by doctor availability, but neither the visit frequency nor the visit fraction appear correlated with available doctor-population ratios in $O E C D$ Health Data. ${ }^{2}$ Differences in remuneration types and cultural differences in seeking medical advice or care may play some role here.

\section{Cross-country differences in income-related inequality in use}

When considering within-country variations in use by income, it is important to emphasize that in almost all of the countries, the concentration indices of actual use (unstandardized, not shown) are negative and mostly significant. This implies that in virtually every OECD country, lowincome groups are more intensive users of doctor services than higher income groups. The differences vary by country, but people in the bottom income quintiles report, on average, about $50 \%$ more doctor visits or about $\mathrm{I} .5$ extra visits per year than those in the top quintiles. However, these utilization differences by income group do not tell us anything about inequity since they may reflect differences in the need for doctor care. It is therefore more appropriate to look at the need-standardized use of physician services. Strictly speaking, for horizontal equity to hold, this use ought not to be systematically related to income. Total use was broken down further into the probability of any use and into conditional use (i.e., given at least one visit). This is of interest if the decision to initiate use is more patient-driven and the decision to continue use more doctor-driven. The patterns are by no means identical for the 2 stages of the utilization process.

\section{Inequalities in the probability of visiting a doctor}

The distribution of doctor visit probability is pro-rich, as indicated by positive HI index values for most countries (Fig. 4). The $\mathrm{HI}$ indices are significantly different from zero (confidence intervals not shown here) in 9 countries: Canada, Finland, Italy, Mexico, the Netherlands, Norway, Portugal, Sweden and the United States. No violation of the horizontal equity principle is found in the other 12 countries. This means that only in about half of the countries studied are higher-income people more likely to see a doctor than lowerincome people, given the same need.

But the distributions are quite different for GP and specialist visits. The probability of contacting a GP is fairly equitably distributed by income. The $\mathrm{HI}$ indices are generally small and insignificant, with a few pro-rich exceptions (Canada, Finland and Portugal). The indices that are pro-poor occur in countries with direct access to a medical specialist (Greece, Spain and Germany). But, on the whole, the likelihood of see-

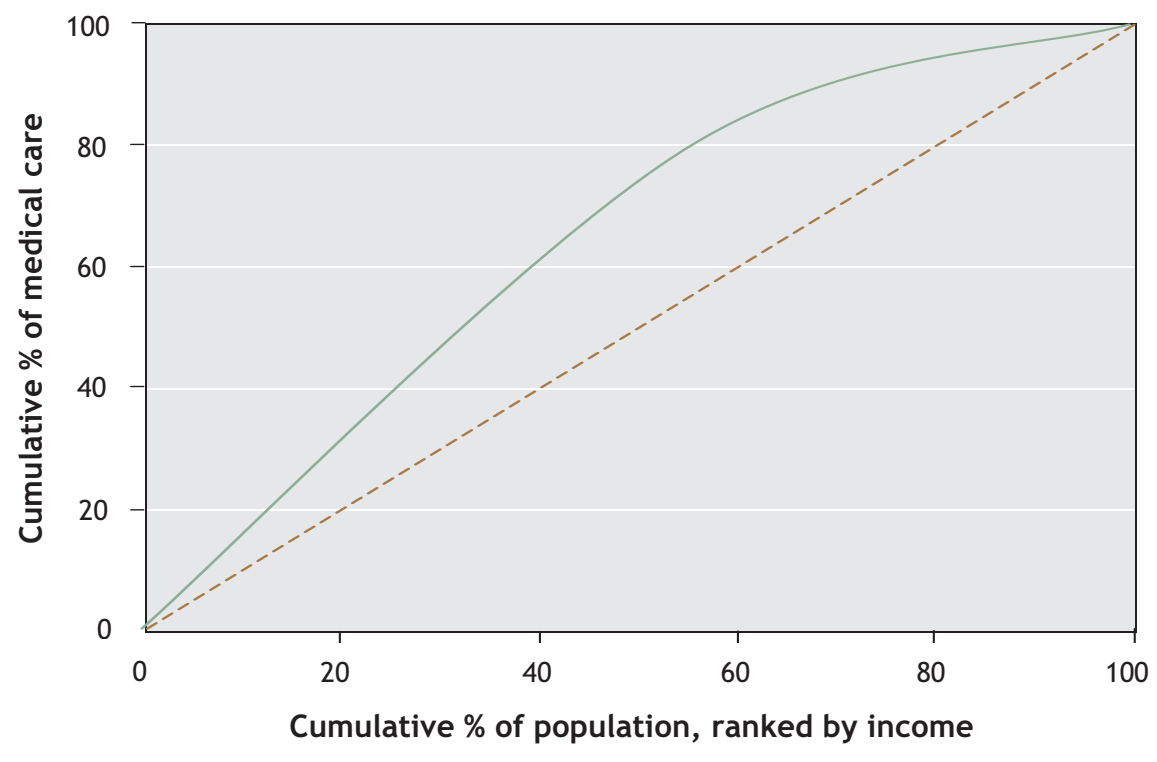

Fig. 1: Sample of a concentration curve of medical care use. Distribution of use is equal among income levels if the concentration curve coincides with the diagonal; a curve that lies above the diagonal indicates that use is more concentrated among the poor. 


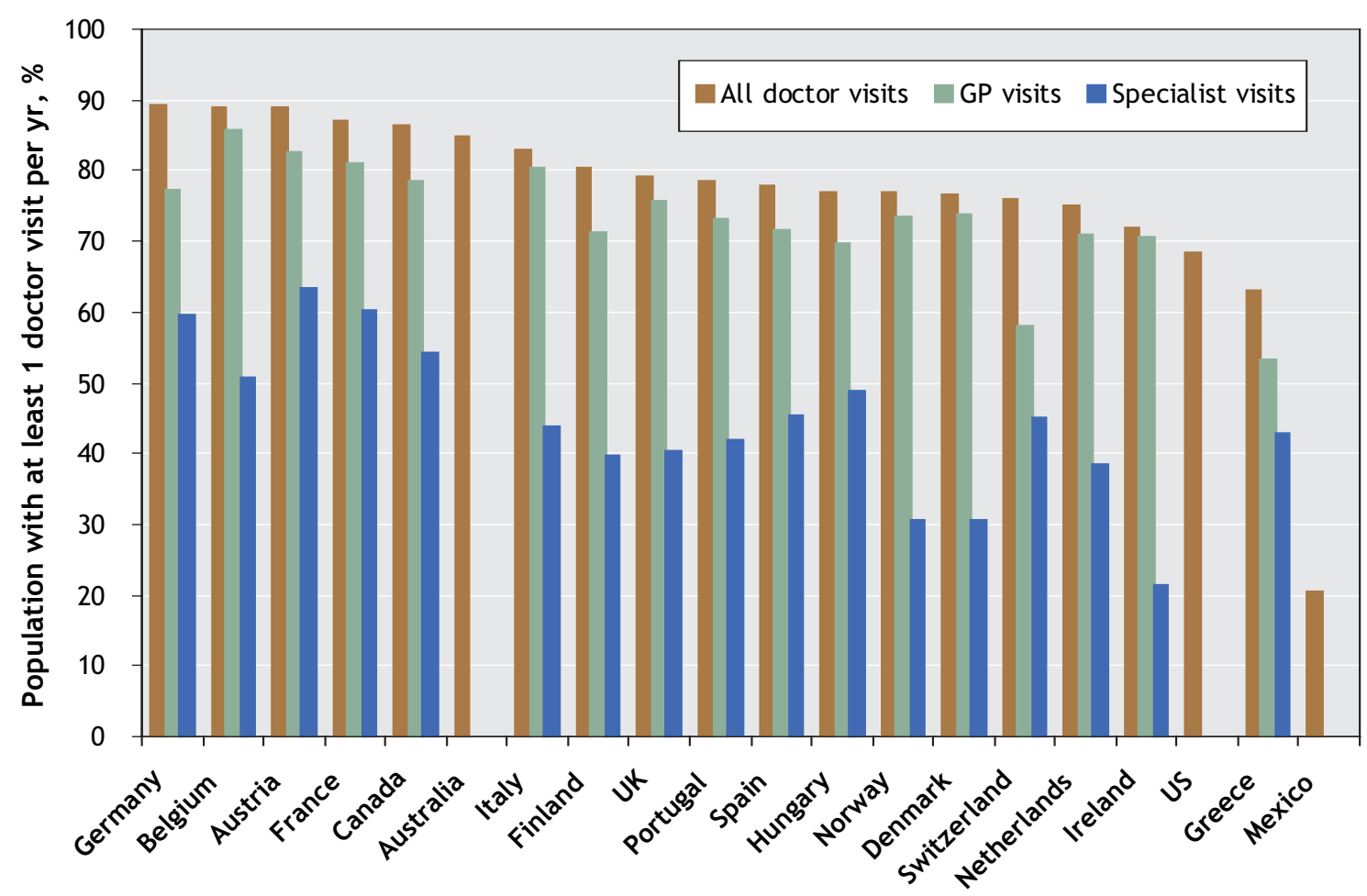

Fig. 2: Proportion of adult population consulting any doctor, general practitioner (GP) or specialist in 19 OECD countries within the previous 12 months. Countries are ranked by the proportion of the population visiting any doctor. UK and German results reflect data obtained in the 1996 ECHP; all other data were obtained in 2000.

ing a GP appears to be distributed according to need, and is not much influenced by income.

The pattern is very different for specialist visits: in all countries, we found significant pro-rich inequity in the likelihood of contacting a specialist. Although there are important differences between countries in the degree to which this occurs, it is clear that, on the whole, access to specialist services does not appear to be equal across income groups. The pattern seen in non-ECHP countries (Canada, France, Hungary, Norway and Switzerland) does not differ much from that of ECHP countries in this respect. Everywhere, given need, higher-income people are more likely to seek specialist care than lower-income people. This is particularly true in countries that offer options to "go private" (e.g., Finland, Portugal, Ireland, Italy and Spain), but it also holds true in countries without such private options and with GP gatekeepers (e.g., Denmark, Norway and Sweden). The finding is much weaker in both the Netherlands, which has no private health care options, and the UK, which does.

\section{Inequalities in mean number of visits}

On the whole, fewer countries show pro-rich inequity indices for the mean doctor visit frequency than for the mean visit fraction (Fig. 5). The HI index is significantly positive (prorich) only in Finland, Portugal, United States, Sweden and Austria, and even significantly negative (pro-poor) for Belgium and Ireland. This means that the conditional number of (nonzero) visits (i.e., given at least one) must favour the poor. Indeed, we found (data not shown) that in several countries, notably Belgium, Canada, Ireland, the Netherlands and Switzerland, $\mathrm{HI}$ indices for conditional number of visits are significantly negative, which indicates inequity favouring the poor. But in another 4 countries, Austria, Finland, Portugal and the United States, the index is still significantly positive. This explains why these countries are among those showing significant positive inequity in all visits. It is, however, important to differentiate between GP and specialist visits, as can be seen for the 17 countries for which this was possible. The need-standardized distributions of GP visits are significantly pro-poor in ro countries. In only one country, Finland, is the $\mathrm{HI}$ index significantly positive (see further discussion of this result below). But given that the GP visit probability was equitably distributed, this must mean that most of the pro-poor distributional pattern in mean visits is generated by a propoor conditional use - in other words, among those with at least one visit per year. In almost every OECD country, the probability of seeing a GP is fairly equally distributed across income, but lower-income patients, once they do see a GP, are more likely to consult more often.

The distributions of visits to a medical specialist show a very different picture. After need standardization, virtually all distributions are significantly in favour of the higher-income groups. The only exceptions are Norway, the Netherlands and the UK, where the HI indices are positive but not significantly different from zero. In most countries, the degree of inequity is somewhat higher in total specialist visits than in the probability of a visit, which suggests that here - in contrast to GP visits - the conditional use (given at least one visit) generally 


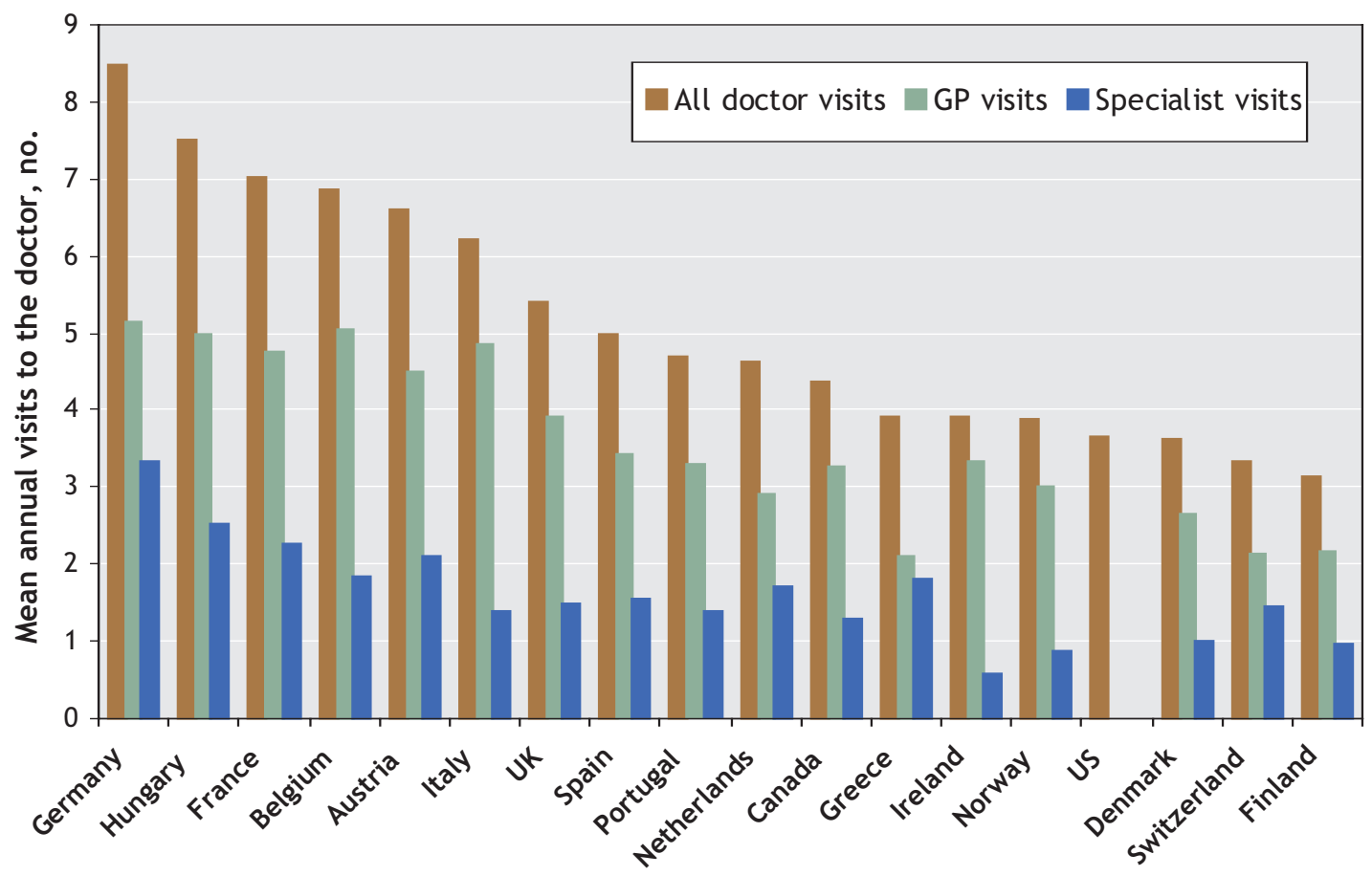

Fig. 3: Annual adult population mean numbers of consultations with any doctor, general practitioner (GP) and specialist in $18 \mathrm{OECD}$ countries in 2000 . Countries are ranked by mean number of doctor visits. UK and German results reflect data obtained in the 1996 ECHP.

reinforces the patterns induced by the inequitable distribution of the probability of any visit.

\section{Interpretation}

In this article we summarize findings from the largest and most comparable analysis of between-country differences and within-country differences by income in doctor visit rates in OECD countries to date. Some of the findings corroborate those obtained in smaller, earlier studies, ${ }^{10,11}$ but they shed further light on the sources of cross-country differences. The results show that people in OECD countries differ tremendously in their average doctor consultation behaviour, but in all of the countries, observed relative distributions around these means tend to favour the lower-income groups. This is because services tend to be distributed according to needs that are likewise concentrated among those who are worse off. Nonetheless, need-standardized distributions tend to favour those who are better off in about half of the countries, for both contact probability and total number of visits, but the degree of this measured inequity is fairly small. The degree of pro-rich inequity in doctor use is found to be highest in the United States and Mexico, the 2 countries without universal coverage of their populations, followed by Finland, Portugal and Sweden.

Breaking down total physician utilization into primary care (GP) and secondary care (specialist) physician visits reveals very divergent patterns. In most countries, GP visits are equitably distributed across income groups, and any significant inequity that emerges is often pro-poor. Pro-poor discrimination through copayment exemptions (as in Ireland) or reduced rates (as in Belgium) seems to play some role here. The only country with a significant pro-rich GP visit distribution is Finland, where some occupational health and private doctor visits were reported as GP visits; primary care visits to doctors in public health centres only have also been found to be pro-poor in Finland. ${ }^{12}$ The picture is very different for medical specialist consultations. The most striking finding is that in all countries, despite the often very different system characteristics, after controlling for need differences, the rich are significantly more likely to see a specialist than the poor and, in most countries, more frequently. Pro-rich inequity is large, and the gradients seem particularly steep in Portugal, Finland, Ireland and Italy, 4 countries where private insurance and direct private payments play some role in the access to specialist services. Surprisingly, this is not the case in countries like the UK. The UK results (which are based on a categorical measure of outpatient rather than specialist visits in the 200I wave of the British Household Panel Survey) are puzzling and in sharp contrast to the strong pro-rich inequity in specialist use found earlier using the 1996 ECHP. ${ }^{11}$ But the results are consistent with recent findings for 1998 2000 from the Health Survey of England, which also suggest a pro-poor distribution of outpatient visits. ${ }^{13}$

Although our study adds considerably to the body of comparative knowledge on the equity achievements of health care systems, it is not without limitations. The available survey data do not allow us to go beyond comparisons of reported quantities of use to examine potential differences in quality of care. Inequities in quality may exacerbate inequities in quantity. ${ }^{14} \mathrm{It}$ is well-known that in many countries, especially those in which private health services are offered alongside public services, not 


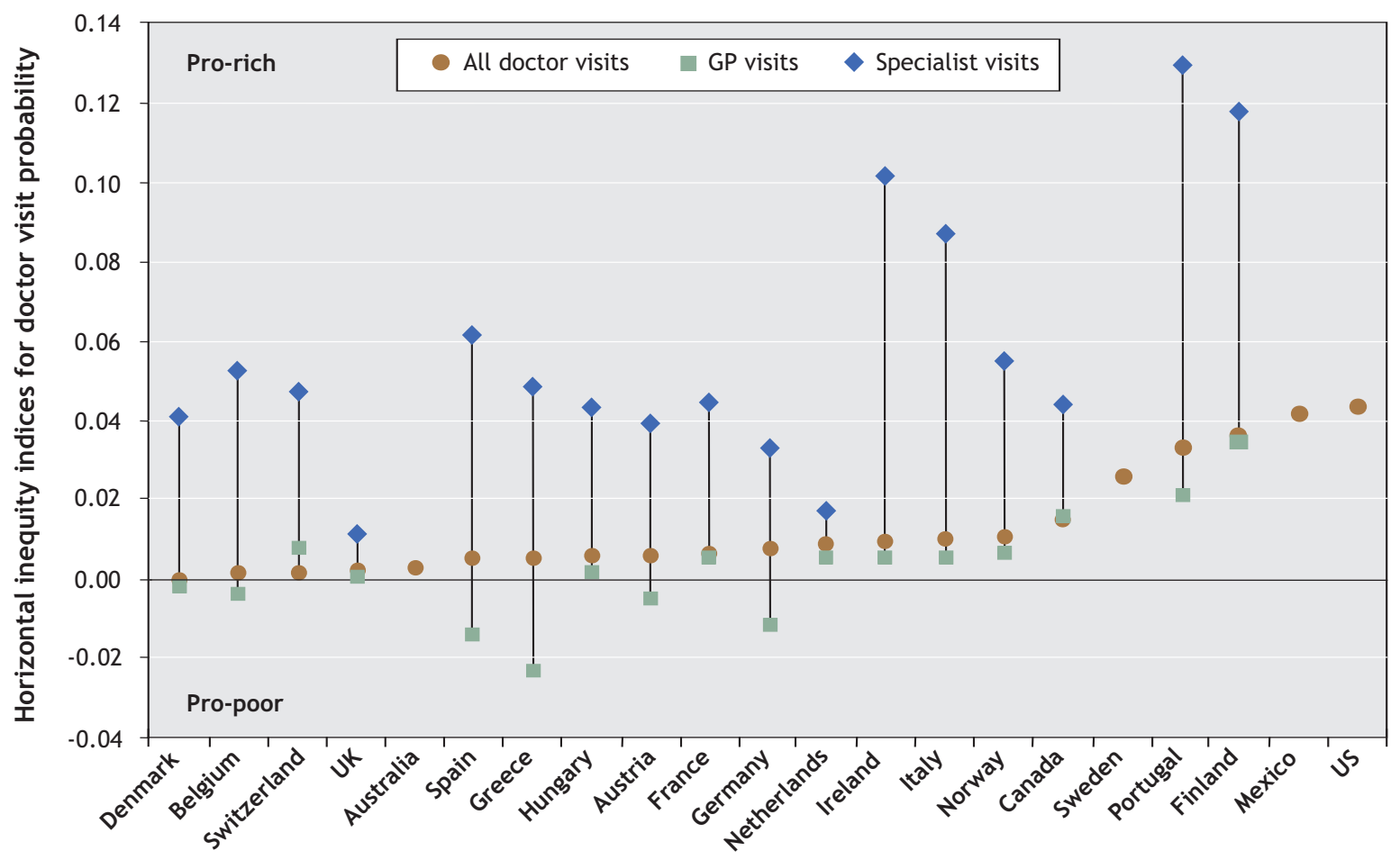

Fig. 4: Horizontal inequity $(\mathrm{HI})$ indices for the annual probability of visiting a doctor in $21 \mathrm{OECD}$ countries. Countries are ranked by $\mathrm{HI}$ for doctor visits. German general practitioner (GP) and specialist indices reflect data obtained in the 1996 ECHP.

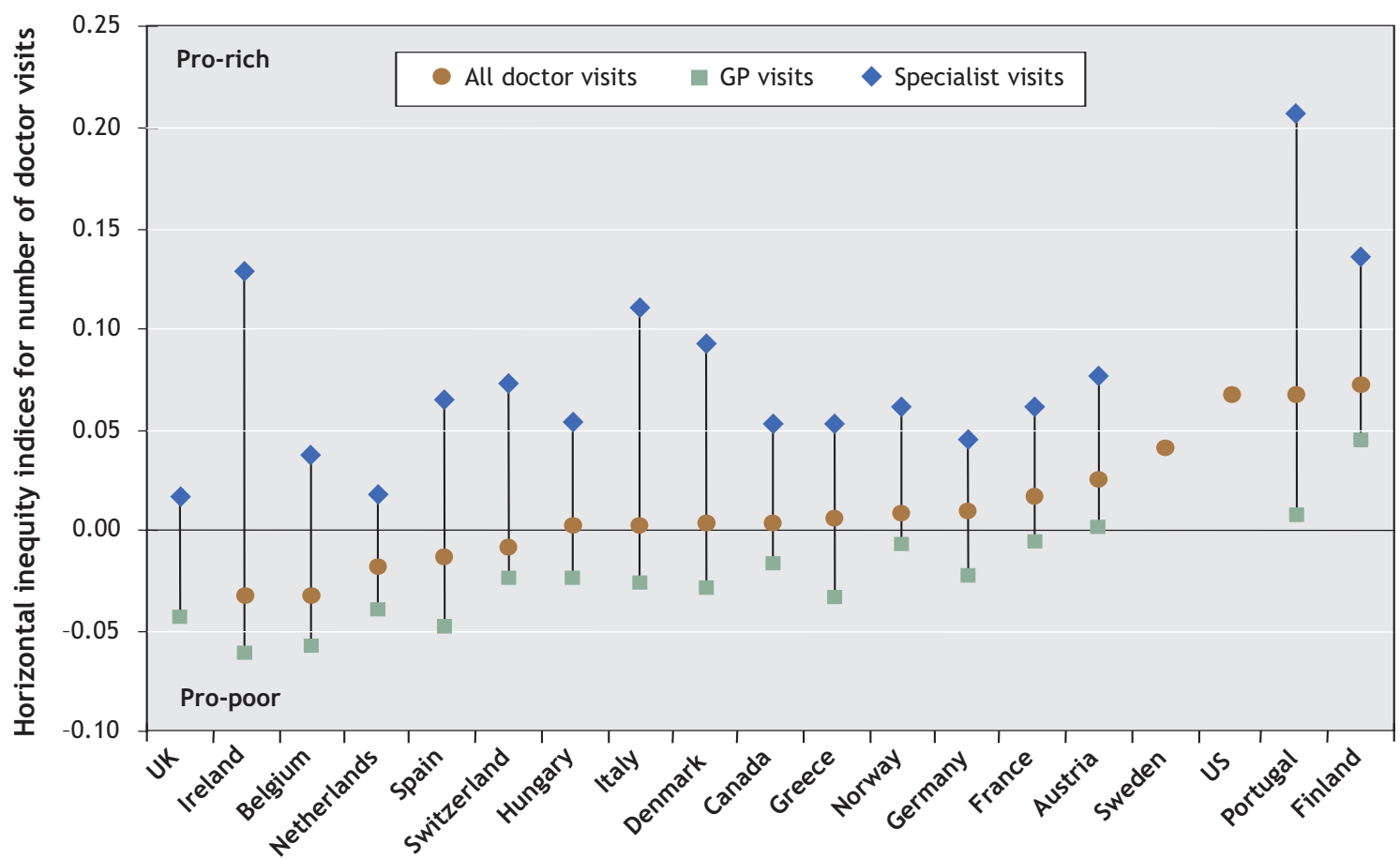

Fig. 5: Horizontal inequity $(\mathrm{HI})$ indices for the annual mean number of visits to a doctor in 19 OECD countries. Countries are ranked by $\mathrm{HI}$ index for doctor visits. German general practitioner (GP) and specialist indices reflect data obtained in the 1996 ECHP. 
all doctor visits can be assumed to be of the same quality. The results of a number of recent studies show that higher-income groups are more likely to use private services. ${ }^{15,16}$ The other obvious area to look into to improve current estimates of inequity is the "needs" adjustment. Clearly, some of the surveys used offer greater potential to measure the care needs of respondents than the common set of simple (though powerful) selfassessed health indicators used in this study. Sensitivity analyses have shown that inclusion of a much larger battery of health measures into the needs adjustment does not change the main thrust of these findings very much, and tends to find more pro-rich (or less pro-poor) inequity. Alternatively, greater need comparability could be obtained by focusing attention on specific treatments for specific subpopulations (e.g., pregnant women, chronically ill patients), but this would come at the price of losing the system-wide perspective.

Finally, an important question is whether and to what extent any inequities in health care usage reported here are not only statistically significant but also policy-relevant. This depends a lot on the extent to which they also translate into inequalities in health outcomes. Evidence of socioeconomic inequities in access to cardiac ${ }^{17}$ and stroke ${ }^{18}$ treatment in Ontario suggests that socioeconomic differences in diagnostic and therapeutic utilization are not trivial and do appear to translate into differential outcomes by income. It seems therefore justified to hypothesize that at least some of the income-related patterns of health care documented here may lead to similar differences in health outcomes.

\section{This article has been peer reviewed.}

From the Department of Health Policy and Management, Erasmus University Medical Centre, Rotterdam, Netherlands (van Doorslaer, Masseria, Koolman); and the London School of Economics, London, UK (Masseria)

\section{Competing interests: None declared.}

Contributors: All of the authors contributed substantially to the study design and execution, data analysis and meetings where preliminary results were discussed, as well as to the drafting of the manuscript and its revision for critical content. All of the authors approved the final version for publication.

Acknowledgements: This study was supported by a grant from the OECD Health Project. The design of the study and the preliminary results were discussed at 2 meetings in Paris, in September and December 2003. The views expressed in this paper are those of the authors and do not necessarily reflect those of their employers or the OECD.

The study was initiated and funded by the OECD Health Project, but its design and execution were the sole responsibility of the authors.

\section{REFERENCES}

I. Hurst JW. Performance measurement and improvement in OECD health systems overview of issues and challenges. In: Measuring up: improving health system performance in OECD countries. Paris: OECD; 2002.

2. Van Doorslaer E, Masseria C; OECD Health Equity Research Group. Income-related inequality in the use of medical care in 2I OECD countries. In: Towards high performing health systems: policy studies. Paris: OECD; 2004. p. Io9-66.

3. Docteur E, Oxley H. Health system reform: lessons from experience. In: Towards high-performing health systems: policy studies. Paris: OECD; 2003. p. 19-85.

4. Van Doorslaer E, Wagstaff A, Rutten F, editors. Equity in the finance and delivery of health care: an international perspective. Oxford: Oxford University Press; 1993.

5. Eurostat. European Community Household Panel (ECHP): selected indicators from the I 995 wave. Luxembourg: European Commission, Eurostat; I999.

6. Van Doorslaer E, Koolman X, Jones AM. Explaining income-related inequalities in doctor utilization in Europe. Health Econ 2004;13:629-47.

7. Wagstaff A, Paci P, van Doorslaer E. On the measurement of inequalities in health Soc Sci Med I99I;33:545-57.
8. Wagstaff A, van Doorslaer E. Equity in health care finance and delivery. In: Newhouse JP, editor. Handbook of health economics. Amsterdam: Elsevier North-Holland; 2000. p. 1803-62.

9. Kakwani N, Wagstaff A, van Doorslaer E. Socioeconomic inequalities in health: measurement, computation and statistical inference. JEconom I997;77:87-103.

Io. Van Doorslaer E, Wagstaff A, van der Burg H, et al. Equity in the delivery of health care in Europe and the US. J Health Econ 2000;19:553-83.

II. Van Doorslaer E, Koolman X, Puffer F. Equity in the use of physician visits in OECD countries: has equal treatment for equal need been achieved? In: Measuring up: improving health systems performance in OECD countries. Paris: OECD; 2002. p. 225-48.

I2. Arinen S, Häkkinen U, Klaukka T, et al. Health and the use of health services in Finland. Main findings of the Finnish Health Care surveys I995/96 and changes from 1987 . Helsinki: STAKES; 1998.

13. Morris S, Sutton M, Gravelle H. Inequity and inequality in the use of health care in England: an extended empirical investigation. York: University of York; 2003.

I4. Fiscella K, Franks P, Gold MR, et al. Inequality in quality: addressing socioeconomic, racial, and ethnic disparities in health care. JAMA 2000;283:2579-84.

15. Rodriguez M, Stoyanova A. The effect of private insurance access on the choice of $\mathrm{GP} / \mathrm{specialist}$ and public/private provider in Spain. Health Econ 2004;13:689-703.

I6. Atella V, Brindisi F, Deb P, et al. Determinants of access to physician services in Italy: a latent class seemingly unrelated probit approach. Health Econ 2004;13:657-68.

17. Alter DA NC, Austin P, Tu JV. Effects of socioeconomic status on access to invasive cardiac procedures and on mortality after acute myocardial infarction. $\mathrm{N} \mathrm{Engl}$ Med I999;34I:I359-67.

I8. Kapral MK WH, Mamdani M, Tu JV. Effect of socioeconomic status on treatment and mortality after stroke. Stroke 2002;33:268-73.

Correspondence to: Dr. Eddy van Doorslaer, Department of Health Policy and Management, Erasmus University Medical Centre, $P O$

Box I738, 3000 DR Rotterdam, Netherlands;

e.vandoorslaer@erasmusmc.nl

\section{Other members of the OECD Health Equity Research Group:}

Gaetan Lafortune (Health Policy Unit, OECD, Paris); Philip Clarke

(Health Economics Research Centre, University of Oxford and

Economics Research School of Social Sciences, Australian

National University); Ulf-G Gerdtham (Department of Community

Medicine, Lund University, Sweden), Unto Häkkinen (Centre for

Health Economics, STAKES, Helsinki, Finland); Agnès Couffinhal and Sandy Tubeuf (IRDES, France); Martin Schellhorn (IZA, Bonn, Germany); Agota Szende (MEDTAP, UK); Gustavo Nigenda (FUNSALUD, Mexico); Astrid Grasdal (Health Economics Department, University of Bergen, Norway); Robert E. Leu (Department of Economics, University of Bern, Switzerland); Frank Puffer and Elizabeth Seidler (Department of Economics, Clark University, Worcester, US)

\section{Editor's take}

- Member countries of the Organization for Economic Cooperation and Development (OECD) include the world's wealthiest nations. However, access to health care may not be equitable across income groups in these countries.

- The authors report the results of a survey study of the general public living in OECD countries. They found that although care from general practitioners was distributed equally, specialist care was biased to patients with higher incomes.

Implications for practice: Richer patients may be more likely to request specialist care; however, it is unknown whether their access to specialist care represents the meeting of a genuine need. Conversely, poorer (and possibly less educated) patients may not advocate for their own health needs as effectively as do patients with higher incomes. 